
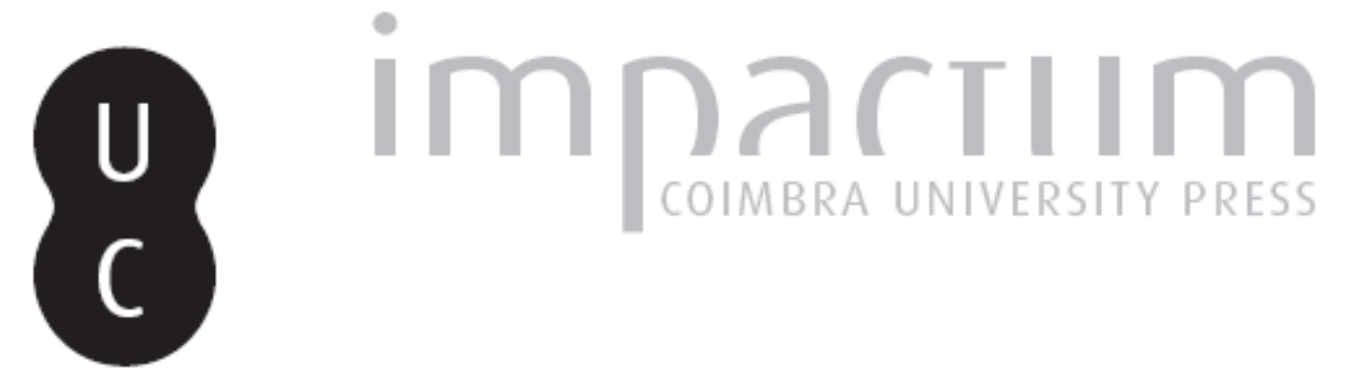

O eucalipto e a cindínica ecológica: "culpado" ou "inocente"?

Autor(es): $\quad$ Ferreira, Carmen Gonçalves

Publicado por: Associação Portuguesa de Riscos, Prevenção e Segurança

URL persistente:

URI:http://hdl.handle.net/10316.2/40151

DOI:

DOI:https://doi.org/10.14195/1647-7723_4_10

Accessed : $\quad$ 26-Apr-2023 11:03:34

A navegação consulta e descarregamento dos títulos inseridos nas Bibliotecas Digitais UC Digitalis, UC Pombalina e UC Impactum, pressupõem a aceitação plena e sem reservas dos Termos e Condições de Uso destas Bibliotecas Digitais, disponíveis em https://digitalis.uc.pt/pt-pt/termos.

Conforme exposto nos referidos Termos e Condições de Uso, o descarregamento de títulos de acesso restrito requer uma licença válida de autorização devendo o utilizador aceder ao(s) documento(s) a partir de um endereço de IP da instituição detentora da supramencionada licença.

Ao utilizador é apenas permitido o descarregamento para uso pessoal, pelo que o emprego do(s) título(s) descarregado(s) para outro fim, designadamente comercial, carece de autorização do respetivo autor ou editor da obra.

Na medida em que todas as obras da UC Digitalis se encontram protegidas pelo Código do Direito de Autor e Direitos Conexos e demais legislação aplicável, toda a cópia, parcial ou total, deste documento, nos casos em que é legalmente admitida, deverá conter ou fazer-se acompanhar por este aviso. 


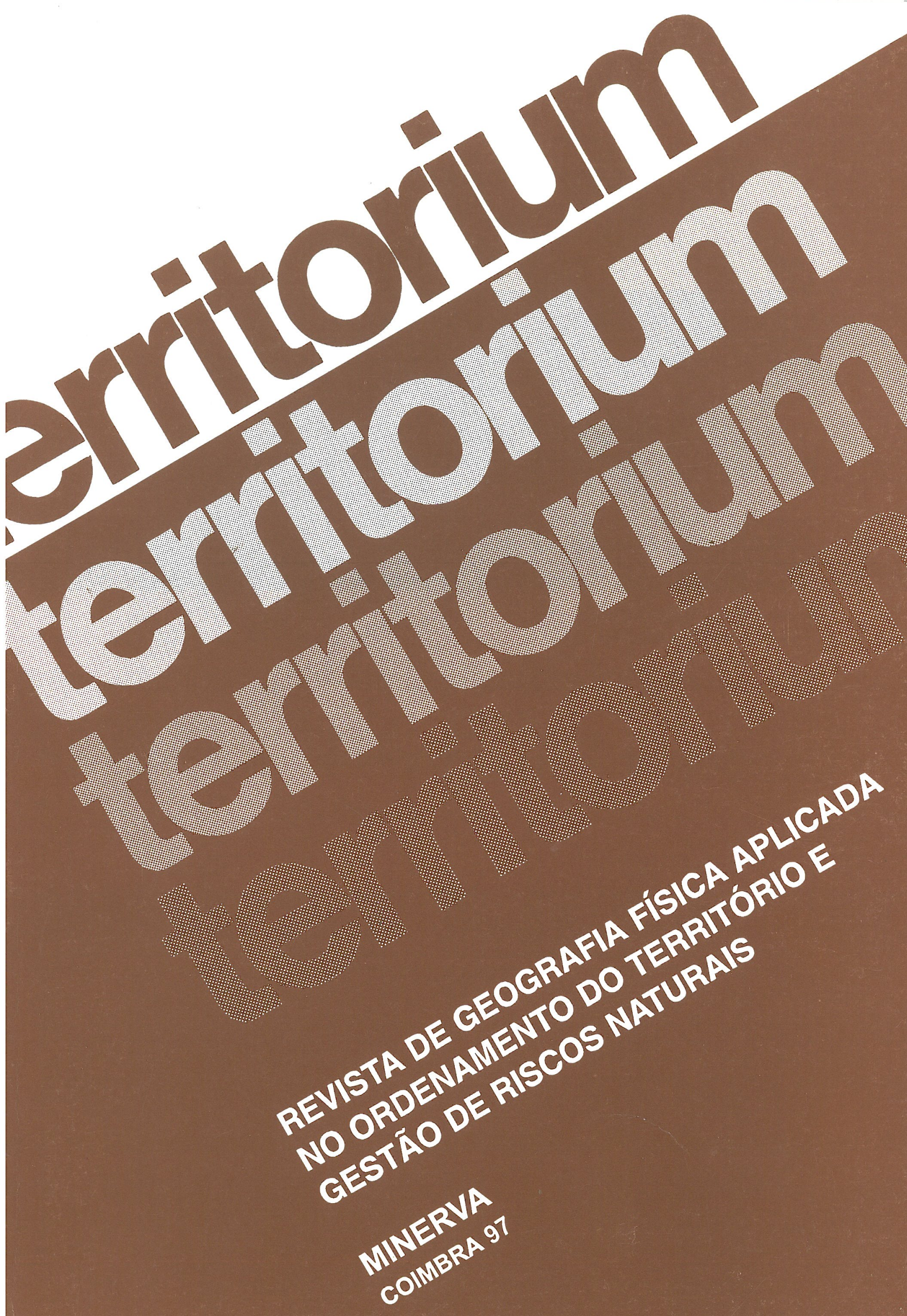




\title{
O eucalipto e a cindínica ecológica: "Culpado" ou "Inocente"?
}

\author{
Carmen Gonçalves Ferreira*
}

\begin{abstract}
Resumo:
Com este artigo, pretende-se que o eucalipto, ao assumir um verdadeiro protagonismo, sirva de base a uma discussão, desapaixonada, sobre os potenciais impactes que esta espécie florestal exerce no solo em termos de produçẫo de escoamento superficial e erosão hídrica.

Palavras Chave:

Incêndios Florestais, Ciências Cindínicas, Eucalyptus globulus, Pinus pinaster, escoamento superficial, erosão de solos, Macieira de Alcôba - Águeda (Portugal).
\end{abstract}

Résumé:

Avec cet article, on prétend que l'eucalyptus, qui assume aujourd'hui un véritable protagonisme, soit le support d'une discussion, sans passion, sur les impacts potentiels que cette espèce forestière exerce sur les sols en ce qui concerne la production de l'écoulement superficiel et de l'érosion hydrique.

Mots clés:

Incendies forestiers, Sciences Cindyniques, Eucalyptus globulus, Pinus pinaster, écoulement superficiel, érosion des sols, Macieira de Alcôba - Águeda (Portugal).

\footnotetext{
Abstract:

In this paper we assume that eucalyptus, having gained a true protagonism, can be the basis of an impartial discussion about the potential impacts this forest tree species can have on the soil, in terms of runoff yield and water erosion.

Key words:

Forest fires, Cindynics sciences, Eucalyptus globulus, Pinus pinaster, runoff, soil erosion, Macieira de Alcôba - Águeda (Portugal).
}

\section{Introdução}

Os incêndios florestais têm sido um dos graves problemas nacionais na maioria dos estios destas duas últimas décadas. Milhares de hectares de área florestal têm sido dizimados pelo fogo (F. REBELO, 1996).

O uso do solo nas áreas onde ocorrem os incêndios tem-se modificado radicalmente. Esta modificação do uso do solo surge, não só como consequência directa dos próprios incêndios, como também em resultado da desertificação social, da crise da agricultura tradicional e da chegada de novas pressões como, por exemplo, o interesse por parte das indústrias da celulose e do papel, no cultivo massivo de espécies arbóreas de rápido crescimento como o eucalipto.

\footnotetext{
* Instituto de Geografia. Faculdade de Letras. Universidade do Porto.
}

São, sobretudo, os proprietários particulares que, na procura de uma legítima rentabilização das terras, optam por esta espécie de rápido crescimento, que exploram em regime de talhadia com cortes em cada 8 a 12 anos.

Em Macieira de Alcôba, freguesia serrana do interior do concelho de Águeda - área que serviu de suporte físico à nossa investigação e que se apresentará como área de estudo -, a evolução do uso do solo nestas últimas décadas, é um exemplo do que referimos anteriormente, ou seja, fez-se como consequência directa dos incêndios florestais que aí ocorreram, criando oportunidade ao aparecimento do eucalipto.

A par da intensificação dos fogos florestais e destes novos padrões de uso do solo, assiste-se, sobretudo na década de 80 , à eclosão da "febre do verde" eà irresistível ascensão das Ciências Cindínicas 
ou Ciências do Perigo. Subitamente, os fogos florestais captam a atenção da opinião pública sobre a floresta e despertam a consciência sobre a sua importância para as gerações vindouras, ou seja, defende-se o seu uso sustentado.

Novos vocábulos surgem numa terminologia cindínica que são aplicados, por vezes com algum excesso, numa nova linguagem de "cassete verde" por aqueles que se lançam em socorro do ambiente, sem a mínima hesitação e sem que antes reconsiderem sobre a intensidade dessas palavras. Deste modo, palavras, como-eucaliptização-, surgem na consciência colectiva como "tragédia" e a designação de "catástrofe ecológica" é utilizada como se se quisesse exorcizar a nossa negligência recente.

$\mathrm{O}$ recalcamento cindínico corresponde a uma tentação permanente de negar ou substimar o perigo e acontece, frequentemente, quando os agentes são múltiplos, os interesses antagónicos, as prioridades outras..., ou seja, quando o processo de tomada de decisão pertence a uma classe política onde os interesses políticos se sobrepõem aos interesses ecológicos e ambientais. O clima emocional que se tem gerado à volta do eucalipto e os lobbies "pró" e "contra" têm obrigado a um esforço adicional de pesquisa no sentido de se encontrarem justificações científicas para alguns dos argumentos frequentemente evocados.

Neste sentido, e através dos resultados apresentados neste trabalho, pretendemos questionar-nos e contribuir, de alguma forma, para uma discussão desapaixonada sobre se a eucaliptização constituirá um risco natural em termos de erosão hídrica dos solos. Será o eucalipto "culpado" ou "inocente"?

\section{A área de estudo}

Macieira de Alcôba está situada na vertente ocidental da Serra do Caramulo. Inscreve-se na vertente norte da bacia hidrográfica do rio Águeda e tem altitudes compreendidas entre os 180 metros, junto ao rio Águeda e os 762 metros na Serra da Urgueira (fig. 1). Predominam em Macieira de Alcôba as vertentes convexas com declives médios próximos dos $20^{\circ}$. Os solos são Cambissolos Húmicos e o material rochoso granítico.

Possui invernos frescos, em que a temperatura mínima média do mês mais frio oscila entre os 2 e os $4^{\circ} \mathrm{C}$, e verões moderados com temperaturas máximas médias do mês mais quente variando entre os $23 \mathrm{e}$ os $29^{\circ} \mathrm{C}$. O valor médio da precipitação anual é de 1878 $\mathrm{mm}$.

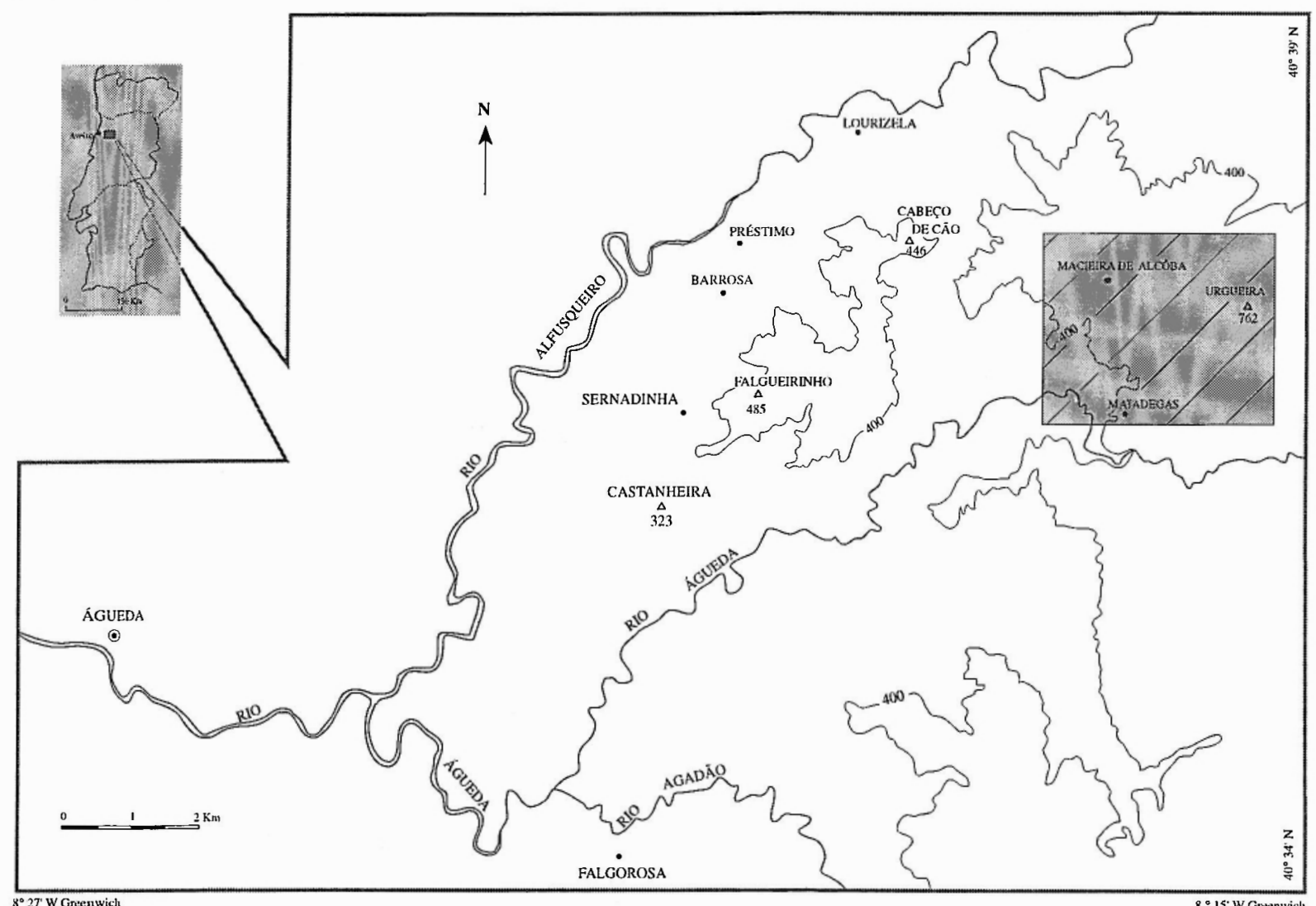

Fig. 1 - Localização geral da área de estudo. 


\section{Os incêndios florestais e as modificações do uso do solo em Macieira de Alcôba}

Até 1932, Macieira de Ålcôba possuía largos baldios povoados a carvalho e sobreiro. É a partir desta data e depois de distribuídos os terrenos baldios por todos os fogos da aldeia que, de acordo com a política florestal de então, começam a surgir extensas áreas de pinheiro bravo que se contrapunham às pequenas manchas agrícolas que ladeavam as áreas construídas dos diferentes lugares de Macieira de Alcôba. Este cenário, que se manteve até meados da década de sessenta, está bem patente na figura 2 onde se verifica que praticamente metade da área $(45,8 \%)$ está coberta por pinheiro da espécie Pinus pinaster. O "mato", vegetação rasteira constituída, essencialmente, por urze, giesta, carqueja, tojo, fetos e estrato herbáceo diverso, cobre também uma grande parte da superfície estudada (42\%). Ocorre, fundamentalmente, nas áreas de maior altitude e nos locais onde afloram as rochas graníticas. O eucalipto circunscrevese a pequenas áreas, pelo que a sua representatividade é insignificante (inferior a 1\%).

Foi a partir do fim da década de sessenta que os grandes incêndios começaram a ocorrer em Macieira de Alcôba e os seus efeitos a fazerem-se sentir nas características do coberto vegetal, fundamentalmente em termos de espécies e de densidade arbórea.
Em 1969 ocorreu um dos maiores incêndios que afectou, até hoje, a área de estudo. Embora não existindo cálculos sobre a extensão da área ardida, soubemos, pela população local, que este teria afectado, sobretudo, a área a sul de Macieira de Alcôba. A análise da fotografia aérea de 1974, permitiu-nos, efectivamente, detectar uma área de grande extensão a sul de Macieira de Alcôba onde a vegetação arbórea era escassa e disseminada e onde dominava o mato. Tal facto é notório no mapa de uso do solo de 1974 (fig. 3) onde, cinco anos após o incêndio, grande parte da mancha ocupada em 1965 por pinheiro é substituída, fundamentalmente, pelo mato e pinheiro regenerado. Aproveitando a necessidade de reflorestação das áreas ardidas e dada a proximidade das fábricas de celulose de Cacia e do Caima, os proprietários particulares iniciaram o plantio do eucalipto plantações bem marcadas no vale do Rio de Maçãs, a oeste de Macieira de Alcôba - na perspectiva de uma rentabilização rápida das terras. A área ocupada por esta espécie de rápido crescimento passa então a ser, em 1974, da ordem dos $8,7 \%$ diminuindo a área ocupada por pinheiro $(34,6 \%)$.

De 1969 a 1985, não se registaram incêndios florestais graves em Macieira de Alcôba. A vegetação inicial teve então possibilidade de regenerar (fig. 4) aumentando, assim, a área ocupada por pinheiro bravo $(48,4 \%)$.

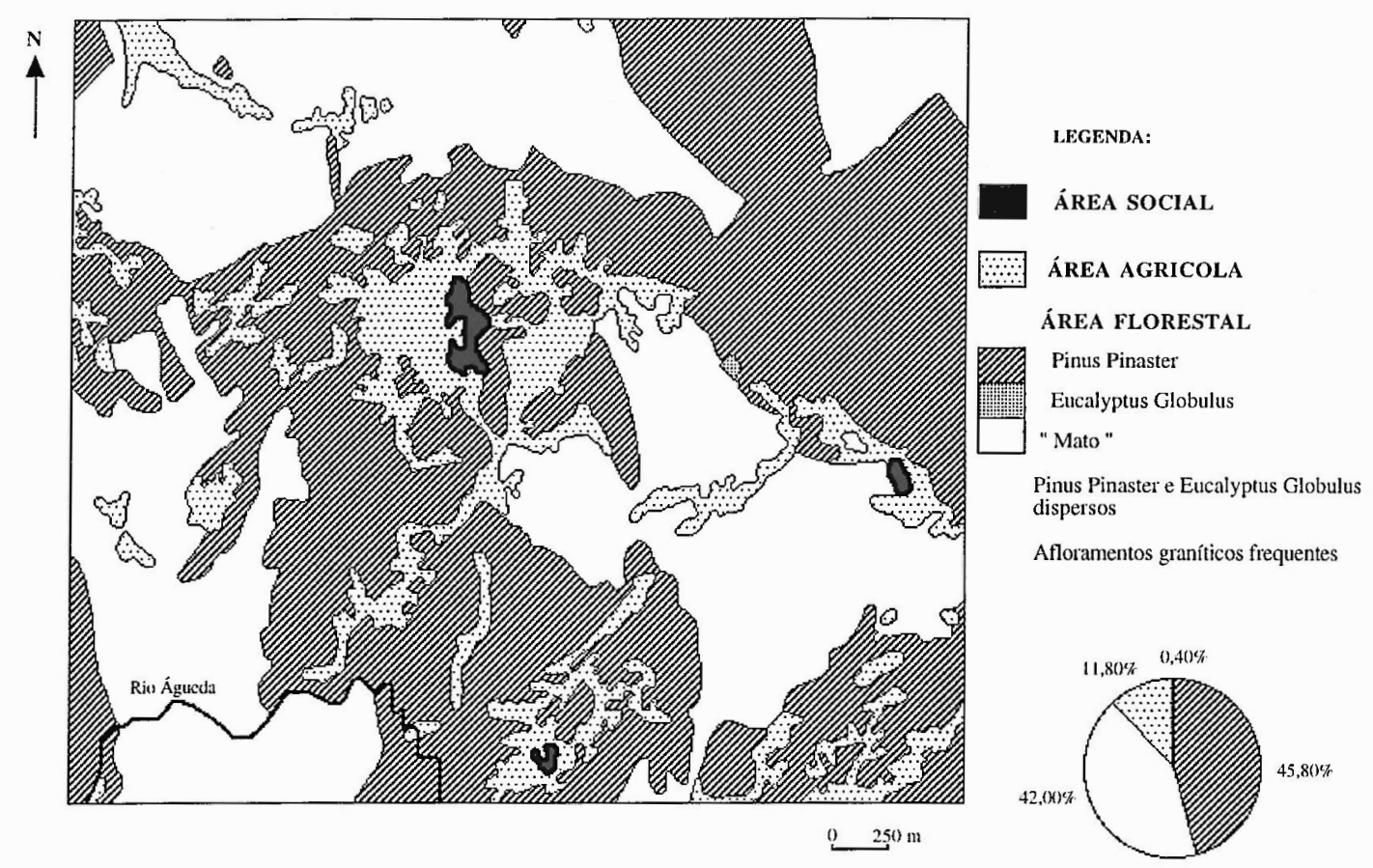

Fig. 2 - Uso do solo em Macieira de Alcôba em 1965. 


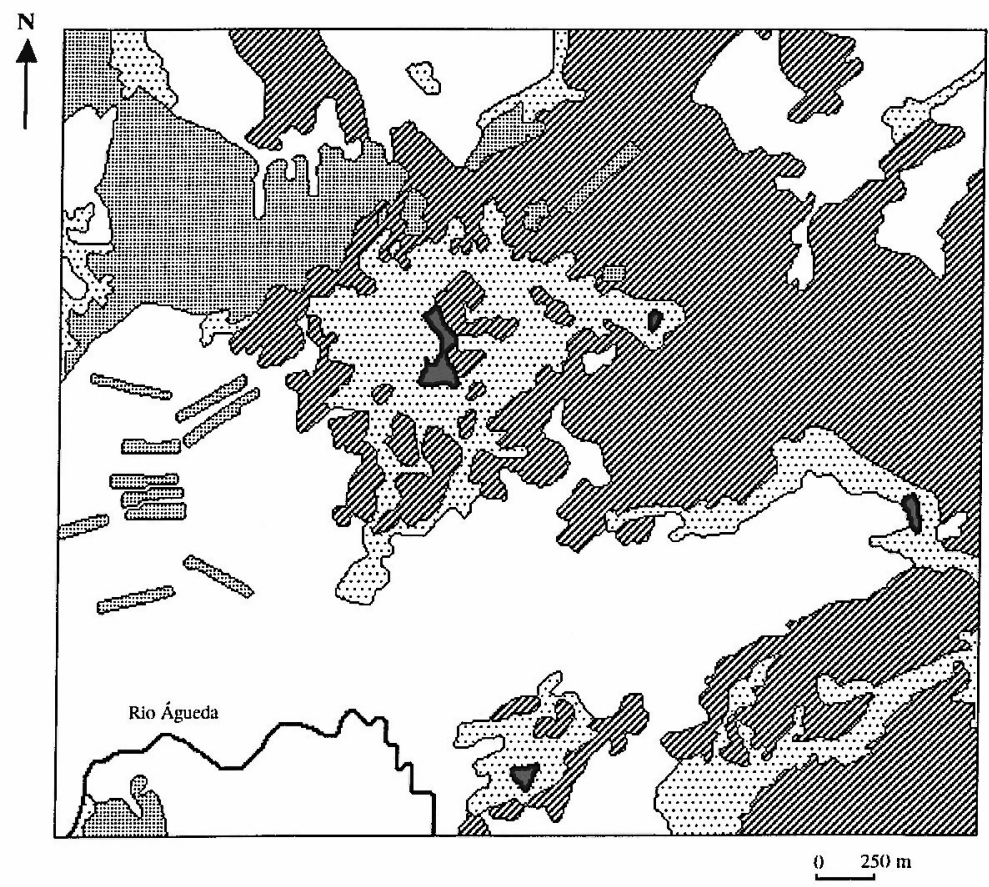

LEGENDA:

área social

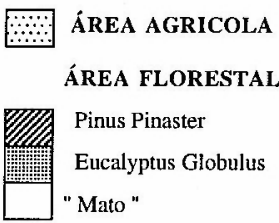

Pinus Pinaster e Eucalyptus Globulus dispersos

Afloramentos graníticos frequentes

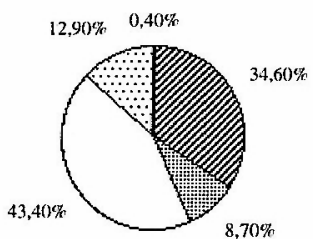

Fig. 3 - Uso do solo em Macieira de Alcôba em 1974.

aumentando, assim, a área ocupada por pinheiro bravo $(48,4 \%)$.

O ano de 1986 ficará registado como um dos anos mais trágicos para a floresta de todo o concelho de Águeda. Nas primeiras horas da manhã do dia 14 de Junho desse ano deflagrou um grande incêndio que teve início em três locais diferentes do concelho:
Castanheira do Vouga, Macieira de Alcôbae Préstimo. Foi responsável pela morte de dezasseis pessoas e pela destruição de 6000 ha de floresta. É novamente a área a sul da aldeia que é a mais afectada pelo fogo (fig. 5) pelo que, no mapa de uso do solo referente a 1989 (fig. 6), três anos após o incêndio, ela aparece com predomínio de mato e com novos retalhos que

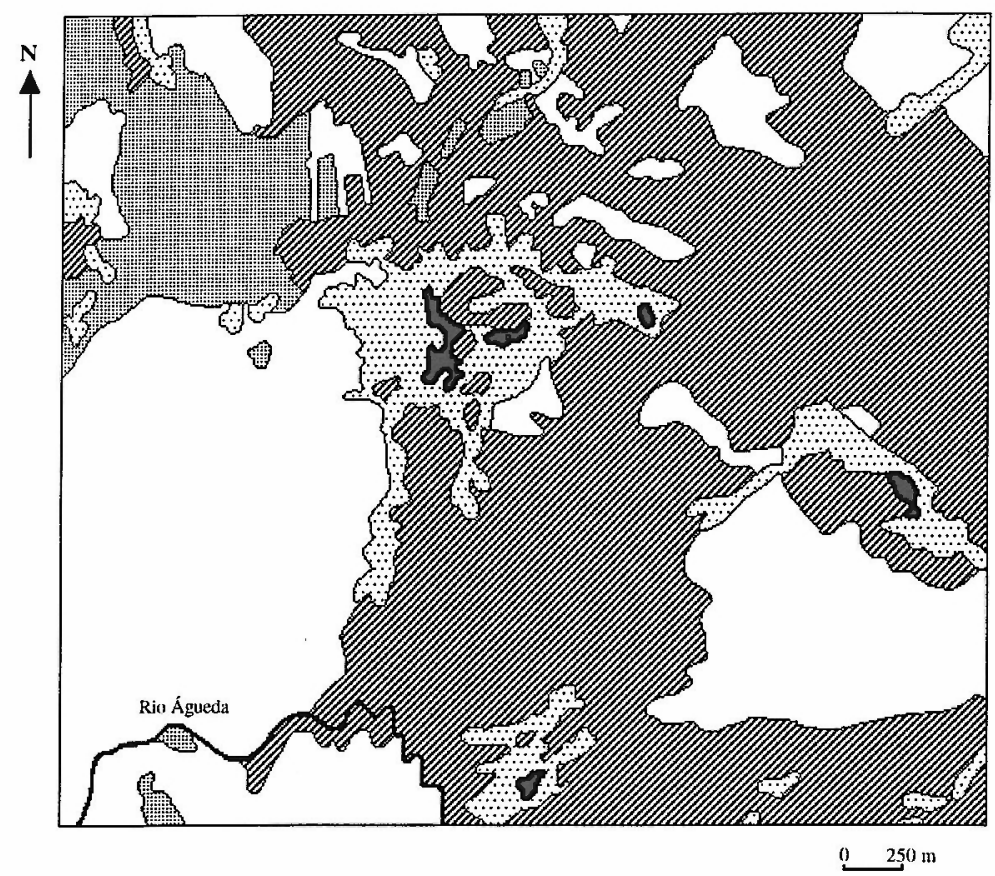

Fig. 4 - Uso do solo em Macieira de Alcôba em 1985.
LEGENDA:

ÁREA SOCIAL

ÁREA AGRICOLA
ÁREA FLORESTAL
Pinus Pinaster
Eucalyptus Globulus
"Mato"

Pinus Pinaster e Eucalyptus Globulus dispersos

Afloramentos graníticos frequentes

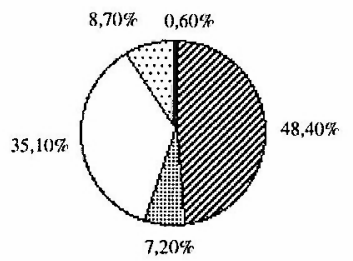



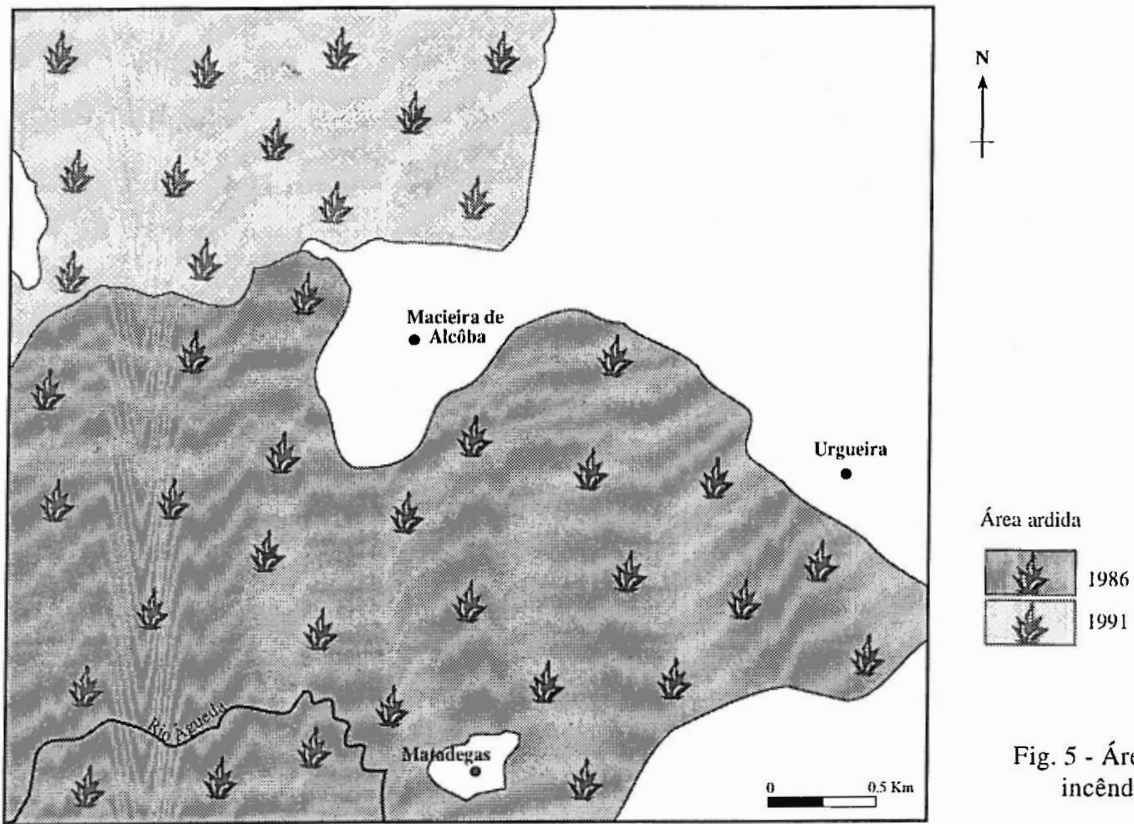

Fig. 5 - Área ardida em Macieira de Alcôba nos incêndios florestais de 1986 e de 1991.

ocupada por pinheiro $(31,5 \%)$ e um ligeiro aumento da área de eucalipto $(11,8 \%)$.

Dois anos mais tarde, em 1991, novo incêndio ocorre afectando, agora, a parte noroeste de Macieira de Alcôba (fig. 5), destruindo uma grande parte da floresta de pinheiro que restava dos anos quarenta.
Surgem novas alterações no uso do solo intensificando-se, como seria previsível, o cultivo do eucalipto. O mapa de uso do solo de 1993 (fig. 7) torna evidente o aumento da área ocupada por esta espécie que passa a ser de $21,75 \%$, em detrimento do pinheiro que vê a sua área reduzida a apenas $23,8 \%$.

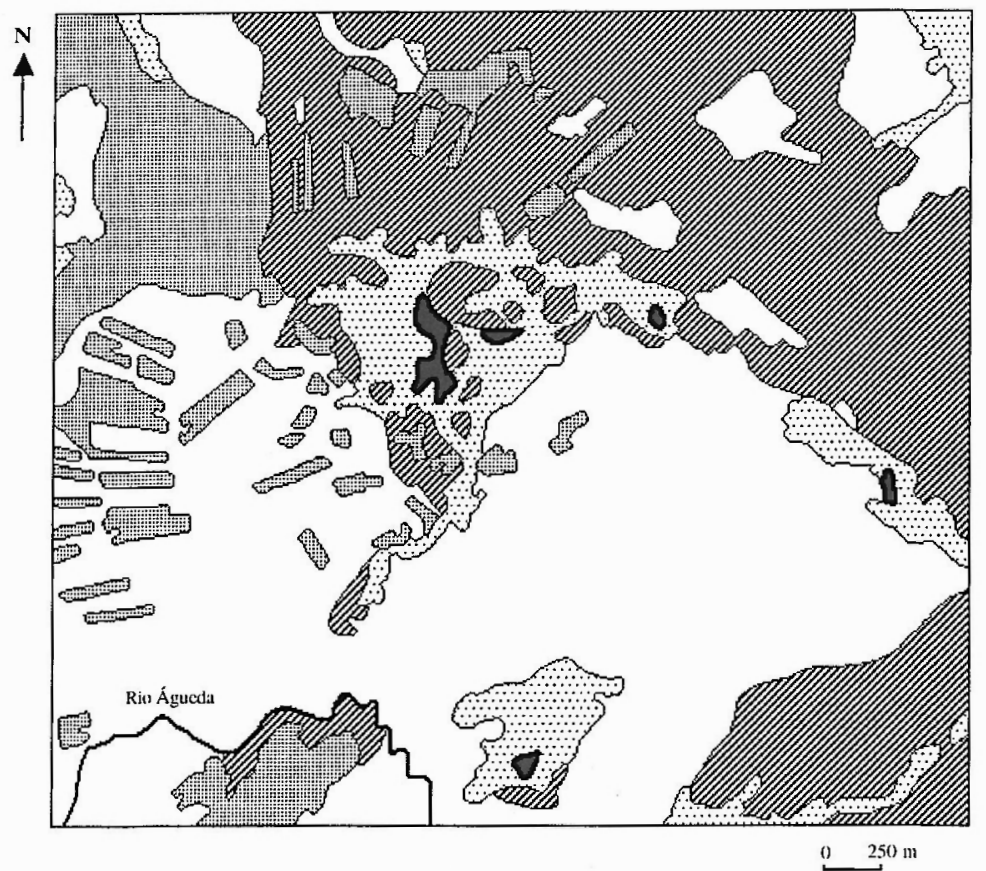

LEGENDA:

área SOCIAL

ÁREA AGRICOLA

ÁREA FLORESTAL

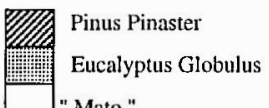

Pinus Pinaster e Eucalyptus Globulus dispersos

A.floramentos graníticos freguentes

Fig. 6 - Uso do solo em Macieira de Alcôba em 1989.

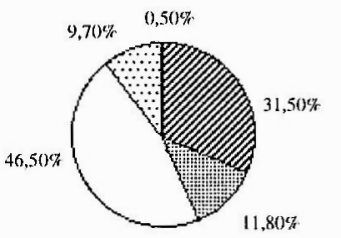




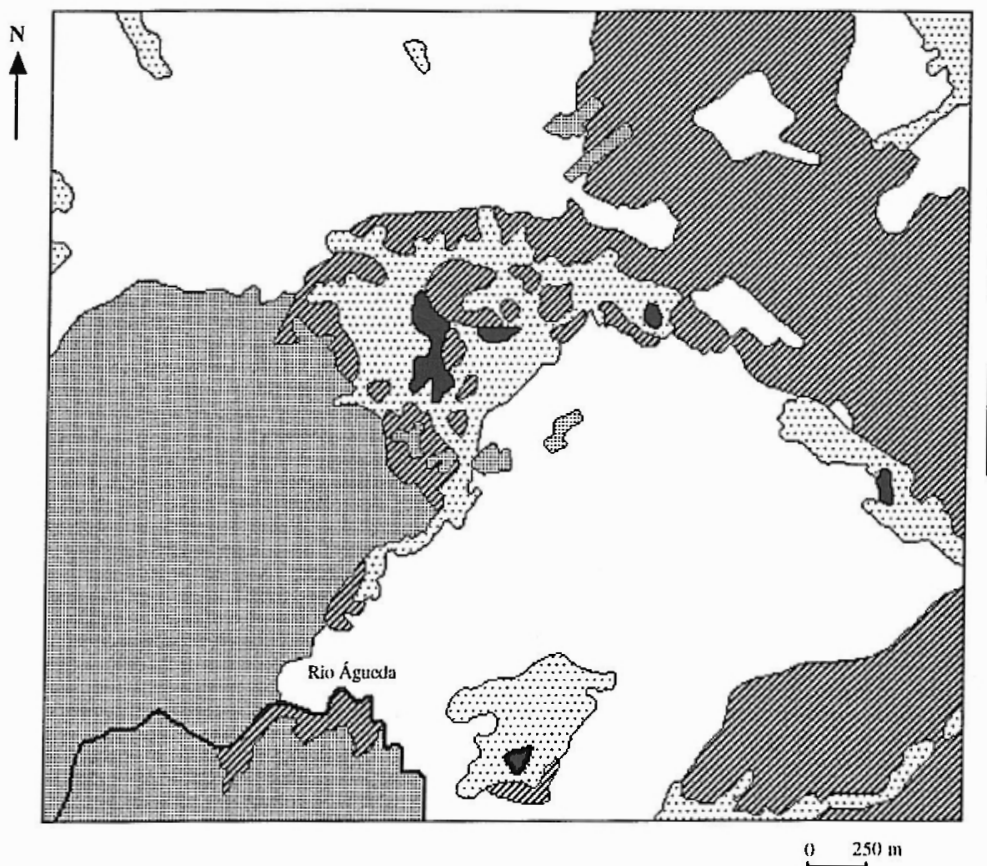

Fig. 7 - Uso do solo em Macieira de Alcôba em 1993.

LEGENDA:

ÁREA SOCIAL

ÁREA AGRICOLA

ÁREA FLORESTAL

Pinus Pinaster

Eucalyptus Globulus

" Mato "

Pinus Pinaster e Eucalyptus Globulus dispersos

Afloramentos graníticos frequentes

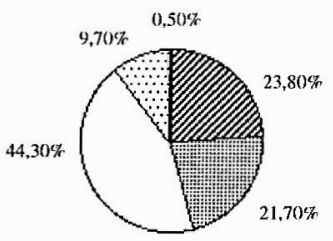

O quadro 1 mostra, de forma resumida, a evolução do uso do solo nos últimos 30 anos. A área ocupada por Pinus pinaster decresceu aproximadamente para metade (de $45,8 \%$ para $23,8 \%$ ), enquanto o Eucalyptus globulus aumentou de $0 \%$ para $21,7 \%$. No quadro 2 podemos constatar que a tendência de substituição da resinosa pela espécie de rápido crescimento se verifica, claramente, a partir do incêndio de 1986. Apenas em sete anos a área de pinheiro apresenta uma variação negativa de $24,6 \%$ enquanto que o eucalipto aumenta a sua área de ocupação na ordem dos $14,5 \%$. O mato, constituído fundamentalmente por espécies pirófitas, perfeitamente adaptadas às características de um incêndio médio, tem, por isso, grande capacidade de germinação e vê a sua área aumentar em cerca de 9,2\%. Chegamos, assim, à situação actual em que o tojo, a carqueja, a giesta, a urze, o feto, etc., dominam claramente a paisagem de Macieira de Alcôba (44,3\%).

\section{Metodologias}

Para a avaliação das perdas de solo delimitaram-se parcelas de erosão experimentais de $16 \mathrm{~m}^{2}(8 \times 2)$ e colocaram-se estacas de erosão em quatro vertentes, previamente seleccionadas, com povoamentos de pinheiro e eucalipto de idades diversas, a saber:

- plantação de eucalipto feita em Maio de 1991 (3 meses);

- pinheiro adulto ( \pm 40 anos $)$ em área não queimada;

- pinheiro regenerado após o incêndio de 1986 (5 anos);

- eucalipto regenerado após o incêndio de 1986 (5 anos).

Em todas as parcelas foram colocadas caixas de erosão, tanques colectores do escoamento superficial, bem como aparelhos de baldes basculantes que permitiam a quantificação da água de escorrência com maior precisão.

$$
\text { Fogo-1969 Fogo-1986 Fogo-1991 }
$$

Quadro 1-Modificações do Uso do Solo en Macieira de Alcôba 1965-1993

\begin{tabular}{|c|c|c|c|c|c|c|c|c|c|c|c|}
\hline \multirow{2}{*}{ USO DO SOLO } & \multicolumn{2}{|c|}{1965} & \multicolumn{2}{|c|}{1974} & \multicolumn{2}{|c|}{1985} & \multicolumn{2}{|c|}{1989} & \multicolumn{2}{|c|}{1993} & \multirow{2}{*}{$\frac{\Delta(1965 / 1993)}{\%}$} \\
\hline & hat & $\%$ & ha & $\%$ & ha & $\%$ & ha & $\%$ & ha & $\%$ & \\
\hline Pinus pinaster & 718 & 45,8 & 543 & 34,6 & 760 & 48,4 & 494 & 31,5 & 373 & 23,8 & $-22,0$ \\
\hline Eucalyptus globulus & 0 & 0,0 & 137 & 8,7 & 112 & 7,2 & 185 & 11,8 & 340 & 21.7 & 21,7 \\
\hline "Mato" & 660 & 42,0 & 681 & 43,4 & 551 & 35,1 & 730 & 46,5 & 696 & 44,3 & 2,3 \\
\hline Área Agrícola & 185 & 11,8 & 203 & 12,9 & 137 & 8,7 & 153 & 9,7 & 153 & 9.7 & $-2,1$ \\
\hline Área Social & 7 & 0,4 & 6 & 0,4 & 10 & 0,6 & 8 & 0,5 & 8 & 0,5 & 0,1 \\
\hline Área Total & 1570 & 100 & 1570 & 100 & 1570 & 100 & 1570 & 100 & 1570 & 100 & \\
\hline
\end{tabular}




\begin{tabular}{|l|c|c|c|}
\hline \multicolumn{1}{|c|}{ USO DO SOLO } & $\mathbf{1 9 8 5}$ & 1993 & $\Delta$ \\
\cline { 2 - 4 } & $\%$ & $\%$ & $\%$ \\
\hline Pinus pinaster & 48,4 & 23,8 & $\mathbf{- 2 4 , 6}$ \\
Eucalyptus globulus & 7,2 & 21,7 & $\mathbf{1 4 , 5}$ \\
"Mato" & 35,1 & 44,3 & $\mathbf{9 , 2}$ \\
Área Agrícola & 8,7 & 9,7 & 1,0 \\
Área Social & 0,6 & 0,5 & $-0,1$ \\
\hline Área Total & 100 & 100 & \\
\hline
\end{tabular}

Quadro 2 - Modificações do Uso do Solo em Macieira de Alcôba $1985-1993$

Fonte: Dados próprios obtidos atravós de fotografia aérea.

Foi também instalado um pluviómetro totalizador, numa área próxima das parcelas, para a quantificação da precipitação.

Para medir a microtopografia do solo foi utilizado o medidor de erosão desenvolvido por Richard Shakesby, que é constituído por uma barra de alumínio de secção quadrada com 1 metro de comprimento e perfurada com 37 orifícios equidistantes (SHAKESBY, 1993).

\section{Apresentação e discussão dos resultados}

O desenho experimental utilizado em Macieira de Alcôba permitiu-nos chegar aos resultados sintetizados no quadro 3 .

O valor de escoamento superficial na plantação de eucalipto, para o período de amostragem (Novembro 92 a Junho 94), foi entre 10 a 20 vezes superior ao observado nas duas parcelas de pinheiro e na de eucalipto regenerado. No eucalipto regenerado, os valores do escoamento superficial produzido por escorrência baixaram significativamente, o que, em termos gerais, coincide com os impactes hidrológicos normalmente imputáveis a povoamentos adultos de outras espécies florestais. Estas diferenças nos valores da escorrência estão, entre outros factores, relacionadas com as diferentes capacidades de infiltração da água no solo calculadas para cada uma das parcelas com um infiltrómetro de duplo anel. Esses valores calculados são, em geral, bastante elevados (entre $411 \mathrm{~mm} / \mathrm{h}$ e $1197 \mathrm{~mm} / \mathrm{h}$ ), próprios de solos com textura franco arenosa, como é o nosso caso, onde a existência de macroporos favorece o processo de infiltração. A elevada percentagem de matéria orgânica no solo da parcela de pinheiro adulto $(17,9 \%$ do peso inicial da amostra de solo)e, pelo contrário, a menor percentagem $(9,1 \%)$ da mesma no solo da plantação de eucalipto, parecem também justificar as diferenças na capacidade média de infiltração de água no solo entre estes dois tipos de cobertos arbóreos, respectivamente, $1197 \mathrm{~mm} / \mathrm{h}$ e $411 \mathrm{~mm} / \mathrm{h}$.

Os valores das perdas de solo encontrados para as diferentes parcelas experimentais permitem-nos afirmar que a plantação de eucalipto é aquela que apresenta uma maior taxa de perda de solo para todo o período de amostragem, cerca de 4 toneladas por hectare $(4380 \mathrm{Kg} / \mathrm{ha})$, enquanto que o pinheiro adulto (65 Kg/ha), o eucalipto regenerado $(44 \mathrm{Kg} / \mathrm{ha})$ e o pinheiro regenerado $(30 \mathrm{Kg} / \mathrm{ha})$, se seguem em termos de ordem de grandeza de perdas de solo. Estes valores de perdas de solo dizem respeito às perdas totais, ou seja, às perdas de sedimento e de matéria orgânica. A análise pormenorizada destas taxas de perdas de solo, permite-nos verificar que a perda de matéria orgânica é sempre superior à do sedimento em todas as parcelas, com excepção da plantação de eucalipto em que a perda de sedimento é da ordem dos $71 \%$. Repare-se, no entanto, nos valores encontrados para o eucalipto regenerado. A perda de sedimento nesta parcela é inferior a todas as outras (11\%), enquanto que a perda de matéria orgânica é a mais elevada ( $89 \%$ ), facto, sem dúvida, relacionado com a grande quantidade de biomassa produzida.

A evolução da microtopografia do solo permite-nos compreender, a uma outra escala de análise, a evolução da respectiva vertente, pois os processos e

\begin{tabular}{|c|c|c|c|c|c|c|c|c|c|c|c|c|c|c|c|c|c|c|c|c|c|c|c|c|c|c|c|c|}
\hline \multirow{4}{*}{$\frac{R}{(m, n)}$} & \multicolumn{7}{|c|}{ PLANTAÇÃO DE EUCALIPTO } & \multicolumn{7}{|c|}{ EUCALIPTO REGENERADO } & \multicolumn{7}{|c|}{ PINHEIRO ADULTO } & \multicolumn{7}{|c|}{ PINHEIRO REGENERADO } \\
\hline & \multirow{3}{*}{$\begin{array}{c}\mathrm{Esc} \\
\mathrm{I} / \mathrm{m} 2\end{array}$} & \multirow{3}{*}{$\frac{\mathrm{CE}}{2 \pi}$} & \multicolumn{5}{|c|}{ Perda de Solo } & \multirow{3}{*}{\begin{tabular}{|l|} 
Esc \\
$1 / \mathrm{m} 2$ \\
\end{tabular}} & \multirow{3}{*}{\begin{tabular}{|l|} 
C E \\
$\%$
\end{tabular}} & \multicolumn{5}{|c|}{ Perdat de Sollo } & \multirow{3}{*}{\begin{tabular}{|c|c} 
Exc & \\
$1 / \mathrm{m} 2$ &
\end{tabular}} & \multirow{3}{*}{\begin{tabular}{|c|}
$C E$ \\
$\%$
\end{tabular}} & \multicolumn{5}{|c|}{ Perda de Solu } & \multirow{3}{*}{\begin{tabular}{|c|} 
Esc \\
$1 / \mathrm{m} 2$ \\
\end{tabular}} & \multirow{3}{*}{$\frac{C \mathrm{E}}{\%}$} & \multicolumn{5}{|c|}{ Perda de Solo } \\
\hline & & & \multicolumn{2}{|c|}{ Sedimento } & \multicolumn{2}{|c|}{ Mat. Org. } & \multirow{2}{*}{$\frac{\text { Total }}{\mathrm{g} / \mathrm{m} 2}$} & & & \multicolumn{2}{|c|}{ Sedimento } & \multicolumn{2}{|c|}{ Mat. Org. } & \multirow{2}{*}{\begin{tabular}{|l|} 
Total \\
$\mathrm{g} / \mathrm{m} 2$
\end{tabular}} & & & \multicolumn{2}{|c|}{ Scdimento } & \multicolumn{2}{|c|}{ Mat. Org. } & \multirow{2}{*}{\begin{tabular}{|l|} 
Total \\
$\mathrm{g} / \mathrm{m} 2$
\end{tabular}} & & & \multicolumn{2}{|c|}{ Sedimento } & \multicolumn{2}{|c|}{ Mat. Org. } & \multirow{2}{*}{$\begin{array}{l}\text { Total } \\
\mathrm{g} / \mathrm{m} 2\end{array}$} \\
\hline & & & $\mathrm{g} / \mathrm{m} 2$ & $\%$ & $\mathrm{~g} / \mathrm{m} 2$ & $\%$ & & & & $\mathrm{~g} / \mathrm{m} 2$ & $\%$ & $\mathrm{~g} / \mathrm{m} 2$ & $\%$ & & & & $\mathrm{~g} / \mathrm{m} 2$ & 学 & $\mathrm{g} / \mathrm{m} 2$ & $\%$ & & & & $\mathrm{~g} / \mathrm{m} 2$ & $\%$ & $\mathrm{~g} / \mathrm{m} 2$ & $\%$ & \\
\hline 3593 & 241 & 6,7 & 310 & 71 & 128 & 29 & 438,26 & 19 & 0,5 & 0,50 & 11 & 3,91 & 89 & 4,41 & 13 & 0,3 & 1,35 & 21 & 5,21 & 79 & 6,56 & 23 & 0,6 & 1,43 & 47 & 1,64 & 53 & 3,07 \\
\hline
\end{tabular}

Quadro 3 - Valores de precipitação (R), escoamento (Esc), coeficiente de escoamento (C E) e perdas de solo obtidas nas diferentes parcelas de erosão (Novembro de 1992 a Junho de 1994) 
a dinâmica que as determinam são idênticos. Os resultados encontrados para as estacas de erosão (quadro 4) corroboram os valores de perdas de solo encontrados nas diferentes parcelas experimentais. Deste modo, a vertente onde foi feita a plantação de eucaliptopoderá evoluir, nesta fase inicial da plantação, de forma mais rápida do que as restantes vertentes, já que foi neste tipo de uso do solo que se verificaram as maiores perdas. Contrariamente ao suposto em termos de senso comum, é no eucalipto regenerado que pode ser considerado pela sua idade ( 6 a 8 anos) como próximo do estado adulto -, que se observa um balanço positivo em todas as medições da microtopografia do solo. Tal facto parece significar que a partir do momento em que o eucalipto atinge uma determinada idade e a sua produção de biomassa é avultada, este passa a exercer uma acção de protecção do solo tanto ou mais eficaz quanto o pinheiro adulto ou regenerado. Aliás, uma das características particulares desta espécie de eucalipto - Eucalyptus globulus -, a mais utilizada em Portugal, é a sua excepcional taxa de produção de biomassa.

\begin{tabular}{|c|c|c|}
\hline & Perfodo de Mediçāo & Ag. 91 - Fev. 94 \\
\hline & Precipitação (mm) & 4497 \\
\hline USO DO SOLO & Estacas & $\begin{array}{c}\text { Perdas/Ganhos (mm) } \\
x\end{array}$ \\
\hline Plantação Eucalipto & $\begin{array}{l}\mathrm{H} 1 \\
\mathrm{H} 2 \\
\mathrm{H} 3\end{array}$ & $\begin{array}{c}-11,23 \\
3,58 \\
-5,34\end{array}$ \\
\hline Eucalipto Regenerado & $\begin{array}{l}\mathrm{J} 1 \\
\mathrm{~J} 2 \\
\mathrm{~J} 3 \\
\mathrm{~J} 4 \\
\end{array}$ & $\begin{array}{l}0,76 \\
6,38 \\
1,02 \\
5,62 \\
\end{array}$ \\
\hline Pinheiro Adulto & $\begin{array}{l}\text { P1 } \\
\text { P2 } \\
\text { P3 } \\
\text { P4 } \\
\text { P5 }\end{array}$ & $\begin{array}{l}7,50 \\
2,27 \\
-3,12 \\
-0,17 \\
-7,04\end{array}$ \\
\hline Pinheiro Regenerado & $\begin{array}{l}\mathrm{A} 1 \\
\mathrm{~A} 2 \\
\mathrm{~A} 3 \\
\mathrm{~A} 4 \\
\mathrm{~A} 5\end{array}$ & $\begin{array}{r}-3,58 \\
-0,38 \\
-2,42 \\
-4,41 \\
-3,51\end{array}$ \\
\hline
\end{tabular}

Quadro 4 - Variações médias da microtopografia do solo para o período de Agosto de 1991 a Fevereiro de 1994

As perdas de solo não apresentam uma relação directa quer com os valores da precipitação, quer com os do escoamento superficial. Esta situação leva-nos a supôr que outras variáveis, como a intensidade do episódio chuvoso e a quantidade de manta morta no solo, não quantificadas no nosso projecto de investigação, terão uma importância maior neste processo erosivo. De facto, é nas parcelas em que abunda a manta morta - caso das parcelas de pinheiro onde uma camada muscínea e de caruma as cobre praticamente a $100 \%$ e da parcela de eucalipto regenerado com a acumulação de ritidomas e folhada -, que se observam as menores perdas de solo. As substâncias húmicas dos solos onde abunda a manta morta criam uma maior estabilidade aos agregados dificultando, deste modo, a remoção das partículas.

Para além da quantidade de manta morta presente no solo, a idade do coberto arbóreo e a densidade do sub-bosque parecem, também, exercer uma forte influência nas taxas de erosão anuais, quando estas são comparadas com idênticos valores de povoamentos da mesma espécie, mas com idades diferentes, obtidos noutros projectos de investigação (FERREIRA, Carmen G., 1996, p. 157-159).

\section{Conclusão}

Perante os resultados globais, parece-nos que se poderá concluir que os impactes do eucalipto, em termos de produção de escoamento superficial e erosão hídrica dos solos, não diferem, na generalidade, do que se considera o "normal" dos revestimentos florestais. Ou seja, é natural esperar que qualquer intervenção que se faça no terreno, em termos de plantação de qualquer espécie, acelere quer as perdas de solo, quer a produção de escoamento superficial, já que se destrói o substrato herbáceo e/ou arbustivo que apresenta um eficaz efeito protector do solo. Os primeiros anos de implantação de um eucaliptal são, efectivamente, desfavoráveis ao meio, por serem etapas em que as reposições de biomassa, por meio de folhas, ramos, ritidomas, etc., são mínimas. Neste caso e atendendo aos nossos valores, parece apenas ser necessário que se tomem medidas de conservação do solo enquanto os povoamentos de eucalipto são jovens, já que, ultrapassada esta fase, estes exercem uma acção de proteç̧ão do solo tão eficaz como a de outras espécies, nomeadamente, o pinheiro.

Sabemos que os escoamentos superficiais são uma das principais componentes das respostas das bacias às precipitações, podendo contribuir, de forma significativa, para a formação de pontas de cheia. Assim, se as bacias florestadas com extensas manchas monoculturais desta espécie de rápido crescimento forem sujeitas a plantio, a cortes rasos extensivos ou a fogos, é de esperar que isso se traduza em produções de escoamento superficial e consequentes perdas de solo particularmente elevadas.

Conscientes destes impactes e à luz de uma ética de responsabilização, é possível tomar-se uma atitude mais interventiva perante o conhecimento de uma potencial situação de risco. No âmbito de uma política de preservação e/ou conservação do solo, os riscos podem ser redimensionados se se proceder a estratégias de risco calculado, que pressupõem técnicas correctas 
de ordenamento florestal. Citem-se apenas algumas, a título de exemplo:

- evitar as extensas manchas monoculturais de eucalipto e promover a plantação de povoamentos arbóreos mistos, de resinosas e folhosas, por forma a permitir as melhores condições de decomposição da folhada;

- evitar os cortes rasos de áreas extensas e a total desprotecção do solo, até que seja assegurada a regeneração natural, ou promover a existência de povoamentos de todas as idades, de forma a que a área cortada anualmente seja aproximadamente constante;

- optar por técnicas de armação do terreno, como por exemplo as técnicas de terraceamento, devidamente concebidas e executadas, de forma a reduzir o escoamento superficial produzido e aumentar a infiltração;

- reduzir a erodibilidade do solo pelo uso de condicionadores sintéticos, geotexteis biodegradáveis, ou adição de resíduos orgânicos no solo nos primeiros anos de implantação de eucaliptos.

Mais importante do que as perdas de solo é a sua degradação. O perigo doeucalipto existe na intensidade relativa de actuação deste processo de degradação física do solo, que dependerá dos factores ambientais próprios da área em causa. Assim, se os incêndios florestais continuarem a afectar Macieira de Alcôba, a combinação dos seus efeitos no solo, conjuntamente com as subsequentes substituições dos povoamentos de pinheiro pelas monoculturas de eucalipto, perspectivam para esta região, se não forem tomadas medidas de conservação, uma degradação do solo e da paisagem.

Sabendo da pouca espessura dos solos desta área teremos que nos questionar sobre quantos ciclos de fogos florestais e de reflorestamentos podem os solos de Macieira de Alcôba suportar, antes do aparecimento dos afloramentos graníticos e de se entrar num caminho, sem retorno, de degradação da paisagem.

\section{BIBLIOGRAFIA}

CANS, Roger (1992) - Verdes. A Encenação Ecológica. Venda nova, Bertrand Editora, 227 p.

FERREIRA, Carmen Gonçalves (1996) - Erosão Hidrica em Solos Florestais. Estudo em Povoamentos de Pinus pinaster e Eucalyptus globulus em Macieira de Alcôba - Águeda. Dissertação de Mestrado em Geografia Física, Coimbra, polic., 186 p.

KERVERN, Georges-Yves (1995) - Elementos Fundamentais das Ciências Cindínicas. Compreender e Prever os Acidentes $e$ Catástrofes. Lisboa, Instituto Piaget, $171 \mathrm{p}$.

REBELO, Fernando (1996) - "Florestas e grandes incêndios florestais no mundo". Territorium, 3, p. 5-10.

SHAKESBY, Richard (1993) - "The soil erosion bridge: a device for micro-profiling soil surfaces". Earth Surface Processes and Lindforms, vol. 18, p. 823-827. 
